\title{
Modelling Past and Future Urban Ecosystem Health Assessment -A Case Study of Kunming
}

Hui Li

South China Agricultural University

Yang Liu

Yunnan University

Weiguo Sheng

Yunnan University

Huiyi Qiu

Yunnan University

\section{Yilu Zhou}

Yunnan University

Xue Huang ( $\sim 576190071 @ q q . c 0 m$ )

South China Agricultural University https://orcid.org/0000-0002-2943-8845

Yanming Chen

South China Agricultural University

Mengran Li

South China Agricultural University

\section{Research Article}

Keywords: Urban ecosystem health assessment, DPSIR model, entire-array-polygon method, Public health, Early warning

Posted Date: April 26th, 2021

DOI: https://doi.org/10.21203/rs.3.rs-390208/v1

License: (c) (1) This work is licensed under a Creative Commons Attribution 4.0 International License. Read Full License 


\title{
Modelling Past and Future Urban Ecosystem Health Assessment
}

\section{-A Case Study of Kunming}

\author{
Hui $\mathrm{Li}^{{ }^{1}}{ }^{*}$, Yang Liu ${ }^{2}$, Weiguo Sheng ${ }^{2}$, Huiyi Qiu ${ }^{2}$, Yilu Zhou ${ }^{2}$, \\ Xue Huang ${ }^{1}$, Yanming Chen ${ }^{1}$, Mengran $\mathrm{Li}^{1}$
}

1. School of Forestry and Landscape Architecture, South China Agricultural University, Guangzhou, 510642

2. School of Architecture and Planning, Yunnan University, Kunming, 650000

*Corresponding author: Hui Li, ydlihui@qq.com.

\begin{abstract}
Rapid urbanisation leads to increasing conflict in the human-environment relationship. The health of urban ecosystems is deteriorating and this will directly harmcommunity health and wellbeing. This paper used Kunming, the capital city of Yunnan Province, China as a case study. A health assessment model for the urban ecosystem of Kunming was built using 25 indicators reflecting five measures: driving force, pressure, state, impact and response. We calculated the indicator values in 2006, 2011 and 2016 with remote sensing and statistical data. We used the entire-array-polygon method to draw polygon graphs and calculate the overall indicator values of the three periods, based on the standardised values of all indicators. All the indicator values were below 0.25 , showing that the urban ecosystem was assessed as unhealthy. On the basis of the past health assessment model, we applied a grey system forecasting method to predict the future health of the urban ecosystem.
\end{abstract}


If the current trends continued, the urban ecosystem would remain in an unhealthy state for 5-10 years. Strong measures should be implemented to improve the overall health of the urban ecosystem. This paper serves as an early warning of the health state of the urban ecosystem in Kunming.

Keywords: Urban ecosystem health assessment; DPSIR model; entire-array-polygon method; Public health; Early warning

\section{Introduction}

The accelerating pace of urbanisation in China is intensifying the destruction of ecosystems in and around urban areas, leading to the emergence of various problems, such as water pollution, loss of cultivated land, deforestation and the heat island effect. The rapid spread of, and uncertainty surrounding, the public health epidemic in early 2020 highlights the importance of urban ecosystem health. Evaluation of the states and values of urban ecosystems health and ecosystem services are prerequisites to improving the wellbeing of urban communities (Naeema et al. 2021). The health of urban ecosystems is fundamental to human health and directly affects the wellbeing of residents (Lu et al. 2015). Research on urban ecosystem health assessment can facilitate systematic understanding of the interaction between humans and nature in urban ecosystems (Steward et al. 2016). On the basis of such quantitative research, it is possible to analyse the relationship between the socio-economic environment and the overall state of urban ecosystem health, thereby providing a reference for the implementation of strategies for the parallel and coordinated improvement of public 
health, ecological conservation and economic growth in the future (Liu et al. 2015).

Studies on the health of cities by researchers outside China began in 1994. Rapport et al. (2015) extended the concept of health in the field of medicine from individuals and populations to ecosystems, and regarded the urban ecosystem as an organic whole to determine its health state; "from this the concept of urban ecosystem health was proposed. This concept refers to a stable and sustainable state for the urban ecosystem; that is, the ecosystem maintains its dynamic characteristics, but it also maintains its inherent stability and is able to resist external threats and pressure (Yang and $\mathrm{Xu} 2002$ ). In recent years, there have been health diagnoses of certain components of cities (such as traffic, organisms, lake and soil) (François et al. 2017, Mahdi et al. 2016, Walker et al.2013), and also assessments of entire cities or urban agglomerations (Su et al. 2012), with a gradual shift towards ecosystem health assessments of entire basins (Pinto et al. 2011). In China, previous studies have focused on assessments of different ecological components such as rivers (Deng et al. 2014, Cao et al. 2018), urban environments (Liu et al. 2016, Zhu et al. 2018), ecological urban areas (Du et al. 2018) and whole urban ecosystems (Su et al. 2010).

To develop an assessment indicator system, researchers have built models mostly from the perspectives of vitality, organisational structure, resilience and ecosystem service function (Lu et al. 2015, Yuan et al. 2019); the study periods have shifted from a single time to dynamic temporal diagnosis and simulation. Furthermore, some studies have adopted geographic information technologies, such as Geographic Information System (GIS), for data analysis. The techniques for research and analysis have been updated constantly, and the 
assessment indicators are relatively unified. In particular, the indicators for assessment models, such as the driving force-pressure-state-impact-response (DPSIR) framework (Zhang et al. 2016), which was modified from the pressure-state-response model (Xu et al. 2017), have been commonly used in the assessments of urban ecological safety and land use status. Compared with other models, the DPSIR model can clearly show the relationship between various factors in a complex system. It is capable of reflecting the relationship between human activities and the ecological environment. In terms of its assessment factors, the DPSIR model considers both the impact of human factors and the current characteristics of the natural environment (Xiong, 2020). This model is, therefore, applicable for establishing an indicator system for the relatively complex and large-scale urban ecosystem of Kunming, China, used in the present study.

The methods of urban ecosystem health assessment include analytic hierarchy process (Chen et al. 2015), fuzzy mathematics (Guan et al. 2014), grey forecasting (Xing and Zhao 2019) and energy analysis (Wang et al. 2018). These methods are all characterised by the determination of indicator weights and, hence, they are highly subjective; their results tend to be non-objective and incomplete. In contrast, the entire-array-polygon method overcomes the limitations of the multivariate statistical methods used commonly in previous studies. This method can eliminate the dimension effects of data with different units, displaying the distinctive, objective and visible characteristics of an assessed object (Zhang et al. 2016). We applied the entire-array-polygon method in the present study.

\section{Study methods}




\section{Study procedure}

In this study, we embedded the DPSIR model into an urban ecosystem health assessment in Kunming, and conducted a dynamic analysis based on the changes in the values of 25 specific indicators representing five measures of the ecosystem (driving force, pressure, state, impact, and response). Following quantitative calculation using the model, we used the entire-array-polygon method to eliminate the effect of unit dimension and subjectivity on the model results. Then, we assessed the overall health level of the urban ecosystem during the study period based on the standardised data. According to the dynamic changes of the indicator values coupled with the actual situation of Kunming, we explored the causes of the observed changes. Finally, we adopted a grey system forecasting model to predict the health of the urban ecosystem in Kunming over the next 10 years and proposed rehabilitation measures based on the prediction results.

\section{The driving force-pressure-state-impact-response (DPSIR) model}

The DPSIR model is an environmental health information framework proposed by the European Environment Agency in 1998( Karen et al. 2010). This assessment model can fully reflect the human-environment relationship, not only indicating the impact of changes in the external factors (such as economy and society) on the environment, but also demonstrating the feedback of the resulting ecological state to society (Wang et al. 2020). The DPSIR model is both systematic and comprehensive (Zhang et al. 2016), wherein D (driving force) represents the initial cause of changes to the existing state or the beginning of the event, namely the potential factors that may drive changes in the ecological environment; $\mathrm{P}$ 
(pressure) represents the direct cause of state changes, namely the factors that directly affect the ecosystem, such as human production and living activities; S (state) represents the appearance and state of the ecological environment under the impacts of the driving force and pressure factors; I (impact) refers to the reaction of the ecological environment to human society under the pressure; and $\mathrm{R}$ (response) represents the measures and means directly or indirectly implemented to restore the ecosystem to the stable state before the pressure (Zhang et al. 2016).

\section{Entire-array-polygon method}

On the basis of the assessment indicator model, the entire-array-polygon method creates a central $n$-sided polygon with the upper limits of $n$ indicators after standardisation as radii. In total, $n$ indicators can form $(n-1) / 2$ different irregular central $n$-sided polygons. The overall indicator value is calculated based on the relationships between the standardised values of different indicators after standardisation with their maximum and minimum values (Zhou et al. 2012), as shown in Eq. (1):

$$
\begin{gathered}
S=\frac{\sum_{i \neq j}^{i, j}\left(S_{i}+1\right) *\left(S_{j}+1\right)}{2 n *(n-1)} \\
S=\frac{\sum_{i \neq j}^{i, j}\left(S_{i}+1\right) \times\left(S_{j}+1\right)}{2 n \times(n-1)}
\end{gathered}
$$

where $S_{i}$ and $S_{j}$ are the standardised values of the $i$-th and $j$-th indicators, respectively; $n$ is the number of indicators; and $S$ is the overall indicator value. The entire-array-polygon method can effectively prevent the effects of human subjectivity during the determination of indicator 
weights in assessment studies, allowing for objective and quantitative assessment of single and overall indicators (Cheng et al. 2013). It has been widely used and has achieved satisfactory results in environmental and resource studies. However, this method has not been applied in the assessment of urban health.

\section{Grey system forecasting method}

The urban ecosystem, as a composite economic-social-ecological system, has typical grey system characteristics, with some information being unclear (Quan et al. 2020). Here, we used the grey system forecasting method to predict the health state of the urban ecosystem in Kunming, China. Because the original data were relatively scattered, ordinary model simulations seldom passed the relevant accuracy tests, and it was difficult to provide exact prediction values. Therefore, we adopted interval forecasting to give a range of future changes, as shown in Eqs. (2-7):

Suppose $X^{(0)}=\left(x^{(0)}(1), x^{(0)}(2), \cdots, x^{(0)}(n)\right)$ is the original sequence, and its 1-AGO sequence is $X^{(1)}=\left(x^{(1)}(1), x^{(1)}(2), \cdots, x^{(1)}(n)\right) ; n$ is the number of original data.

$$
\text { Let } \sigma_{\max }=\max _{1 \leq k \leq n}\left\{x^{(0)}(k)\right\}, \sigma_{\min }=\min _{1 \leq k \leq n}\left\{x^{(0)}(k)\right\}
$$

then the upper-bound function $f_{s}(n+t)$ and lower-bound function $f_{u}(n+t)$ of $X^{(1)}$ are expressed as follows:

$$
\begin{gathered}
f_{s}(n+t)=x^{(1)}(n)+t \sigma_{\max } \\
f_{u}(n+t)=x^{(1)}(n)+t \sigma_{\min }
\end{gathered}
$$

where $t=1,2, \ldots m, m$ is the number of predicted data.

The inverse accumulated generating operation of $X_{s}^{(0)}$ is deduced, 


$$
\hat{x}_{s}^{(0)}(n+t)=f_{s}(n+t+1)-f_{s}(n+t)
$$

The inverse accumulated generating operation of $X_{u}{ }^{(0)}$ is also deduced,

$$
\begin{aligned}
\hat{x}_{u}{ }^{(0)}(n+t) & =f_{u}(n+t+1)-f_{u}(n+t) \\
\Delta_{s \max } & =\max _{n+1 \leq k \leq n+m}\left\{\hat{x}_{s}^{(0)}(k)\right\}, \Delta_{u \min }=\min _{n+1 \leq k \leq n+m}\left\{\hat{x}_{u}{ }^{(0)}(k)\right\}
\end{aligned}
$$

where $\Delta_{s \max }$ and $\Delta_{u \min }$ are the upper and lower bounds of the predicted values, respectively.

\section{Study area and data sources}

\section{Study area}

The study area consists of the six districts and eight counties of Kunming City, which is located between $102^{\circ} 10^{\prime}-103^{\circ} 40^{\prime} \mathrm{E}$ and $24^{\circ} 23^{\prime}-26^{\circ} 22^{\prime} \mathrm{N}$ (Fig. 1). Kunming was a key land hub connecting Southeast and South Asia on the ancient Southern Silk Road during the Western Han Dynasty, and it is also the starting city of the Bangladesh-China-India-Myanmar Economic Corridor, with an important geographical location in the construction of the Belt and Road initiative (Zhu 2020). By the end of 2019, Kunming had a permanent population of 6.67 million. Because of the large urban population and insufficient supply of social public service resources, the fragile ecological environment is under great pressure. 


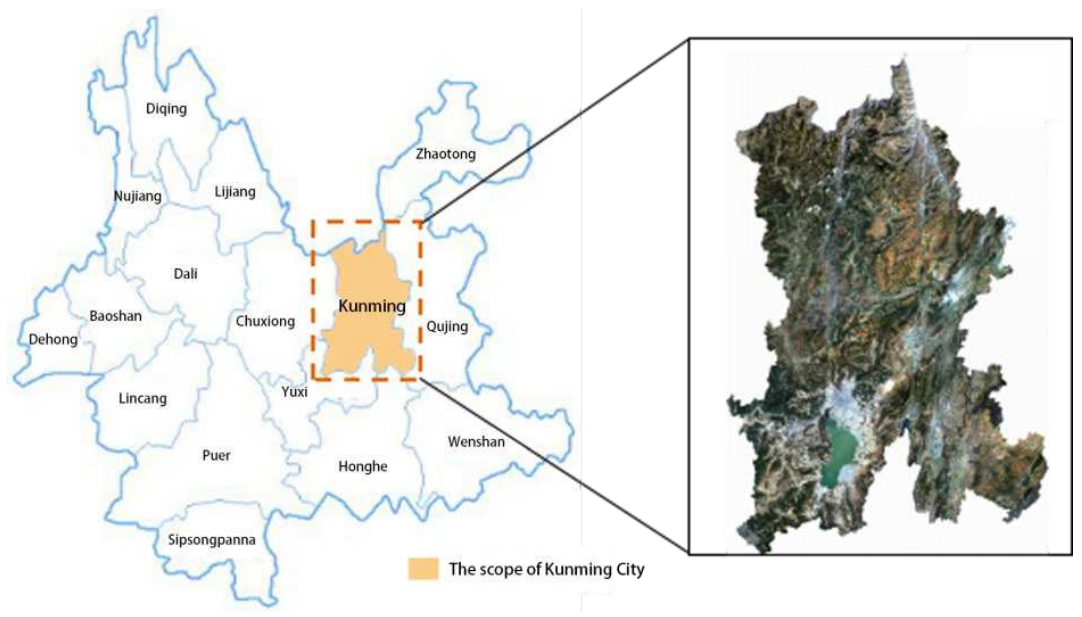

Fig. 1 Scope of the study area in Kunming, Yunnan Province, China

The urban area of Kunming is built on a plateau and more than $80 \%$ of the region is mountainous. Most of the area belongs to a lake basin karst plateau landform with an elevation between 1500 and $2800 \mathrm{~m}$. The most frequent natural disasters are droughts, earthquakes and debris flows. Geological hazards occur frequently and have strong impacts, with an irregular distribution of hazard sites and extremely fragile ecology. Most of the area experiences a low-latitude monsoon climate, with significant seasonal variations. Meteorological hazards such as forest fires, lightning strikes and droughts also occur frequently. Furthermore, as urban expansion continues, the ecological connectivity of rivers, grasslands and forest belts in the city has been interrupted. For example, the rivers feeding into lakes such as Dianchi and Yangzonghai often dry up, while the problem of water pollution in the lakes is critical.

\section{Data sources}

Landsat TM remote sensing imagery for Kunming in 2006, 2011 and 2016 were downloaded from the Geospatial Data Cloud (http://www.gscloud.cn), with a resolution of 30 
$\mathrm{m}$ and a cloud cover of $<10 \%$. Land use was classified from the images and the resulting data were used in this study (Fig. 2). Other data came mainly from the Kunming Statistical Yearbook (2007 and 2012), the Kunming National Economic and Social Development Statistical Bulletin (2016), the Kunming and Yunnan Water Resources Bulletins (2006, 2011 and 2016), the List of Natural Reserves in Yunnan (2006), the List of Nature Reserves in China (2011 and 2016) and the Kunming Bulletin of Environmental Status (2016).

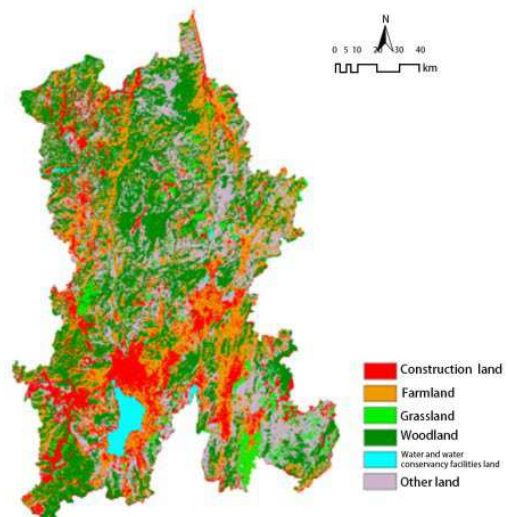

(a) 2006

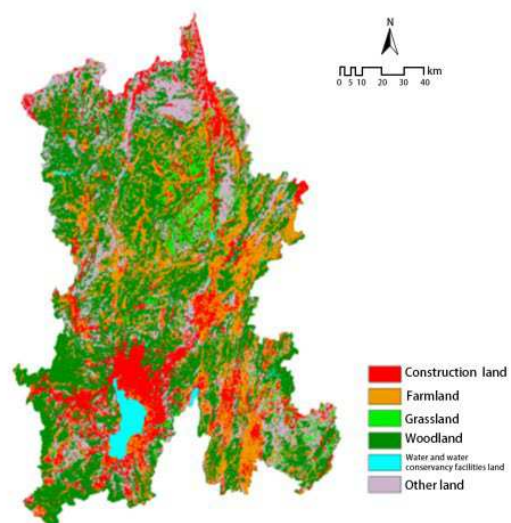

(b) 2011

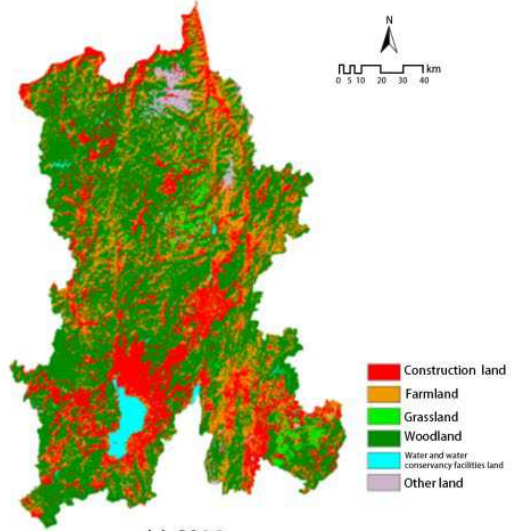

(c) 2016

Fig. 2 Land use classification in Kunming during 2006, 2011 and 2016

\section{Construction of the driving force-pressure-state-impact-response (DPSIR) model and}

\section{assessment indicator system for Kunming}

\section{Construction of the model}

To ensure that the indicators of different factors could accurately and completely reflect the actions and reactions of the ecosystem to the social, economic and natural conditions of the study area, we initially selected a total of 43 indicators from the different factors to design a questionnaire. The selection of the indicators was based on the assessment indicators used in previous studies, combined with the social and natural characteristics of the present study 
area. Seventy questionnaires were sent to experts at the Central South University and Nanjing University, with 56 forms returned. Through data analysis using the Analytic Hierarchy Process software, we ranked the relative importance of various factors corresponding to the indicators. On the basis of data availability, we finally selected 25 indicators to construct the DPSIR model (Fig. 3).

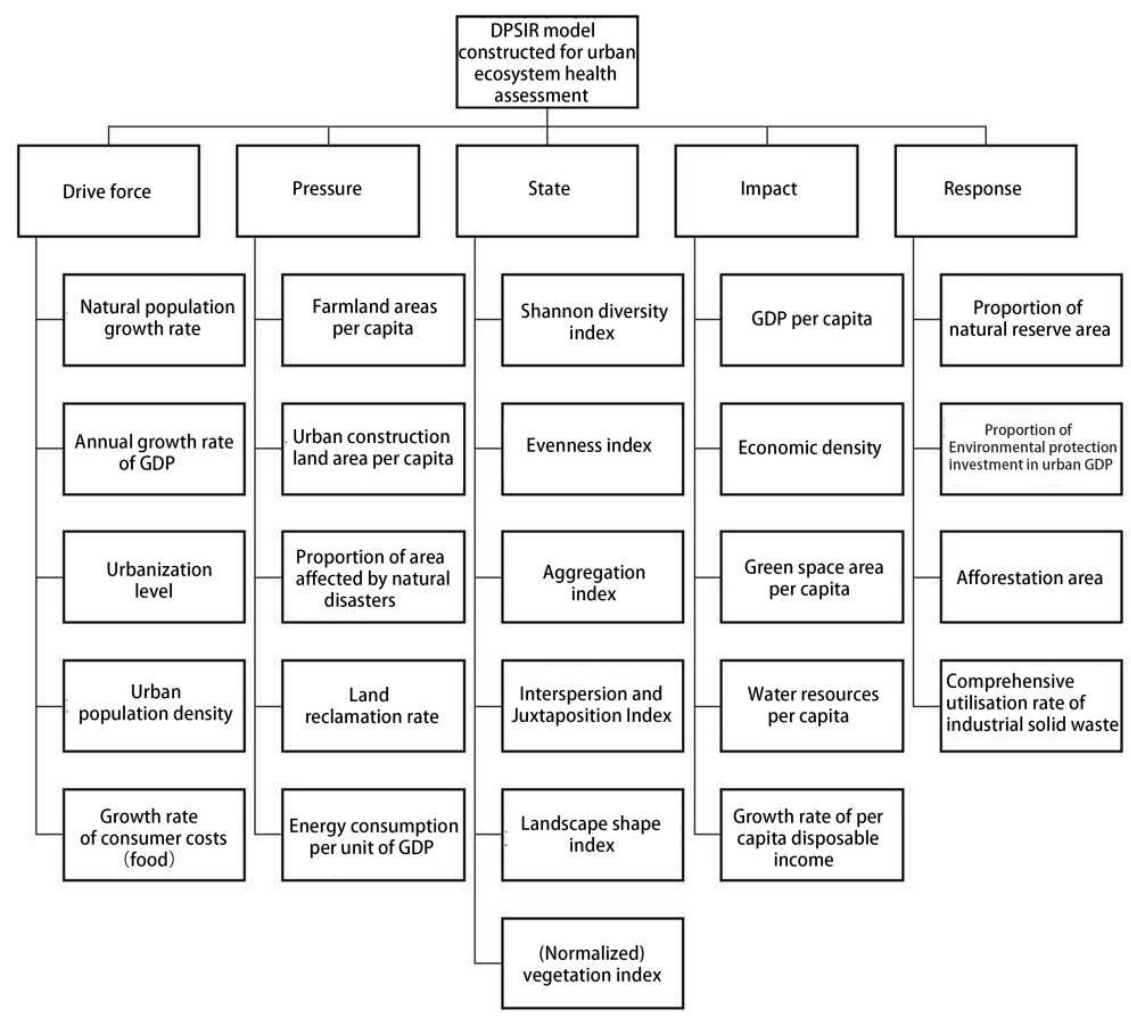

Fig. 3 Diagram of the driving force-pressure-state-impact-response (DPSIR) model constructed for urban ecosystem health assessment

Table 1 Description and calculation method for the indicators for urban ecosystem health assessment

\begin{tabular}{|c|c|c|c|}
\hline Factor & Indicator & Description & Calculation method \\
\hline \multirow{6}{*}{$\begin{array}{l}\text { Driving } \\
\text { force }\end{array}$} & & It indicates the driving force of natural population growth & \\
\hline & Natural population & posed on the changes in the urban ecosystem, and is an & Natural population growth rate $=$ Birth rate of the \\
\hline & growth rate & important indicator reflecting population development & year-Death rate of the year \\
\hline & & speed and formulating population plans. & \\
\hline & Annual growth rate & It indicates the potential impact of urban economic & Annual growth rate of GDP $=$ GDP growth of the \\
\hline & of GDP & development on the urban ecosystem. & year / Total GDP of the previous year $\times 100 \%$ \\
\hline
\end{tabular}




\begin{tabular}{|c|c|c|c|}
\hline & Urbanisation level & $\begin{array}{l}\text { It reflects the process and degree of population } \\
\text { aggregation into the city. }\end{array}$ & $\begin{array}{l}\text { Urbanisation level }=\text { Urban population } / \text { Total } \\
\text { population } \times 100 \%\end{array}$ \\
\hline & $\begin{array}{l}\text { Urban population } \\
\text { density }\end{array}$ & $\begin{array}{l}\text { It reflects the effect of the degree of urban population } \\
\text { aggregation in driving changes in the urban ecosystem. }\end{array}$ & $\begin{array}{l}\text { Urban population density }=\text { Total population } \\
\text { within a geographical range / Land area within } \\
\text { the geographical range }\end{array}$ \\
\hline & $\begin{array}{l}\text { Growth rate of } \\
\text { consumer price } \\
\text { (food) }\end{array}$ & $\begin{array}{l}\text { It reflects the variation characteristics of consumer prices } \\
\text { urban residents' daily necessities, and indicates the } \\
\text { changes in the urban residents' lives. }\end{array}$ & $\begin{array}{l}\text { Growth rate of consumer price }=\text { Growth of } \\
\text { residents' consumer price index for food, tobacco } \\
\text { and alcohol in the study area / Consumer price } \\
\text { index of the previous year } \times 100 \%\end{array}$ \\
\hline \multirow{5}{*}{ Pressure } & $\begin{array}{l}\text { Farmland area per } \\
\text { capita }\end{array}$ & $\begin{array}{l}\text { It reflects the pressure on the ecosystem due to the } \\
\text { consumption of ecosystem resources by the basic cost of } \\
\text { living required by urban population. }\end{array}$ & $\begin{array}{l}\text { Farmland area per capita }=\text { Total farmland area } / \\
\text { Total permanent population }\end{array}$ \\
\hline & $\begin{array}{l}\text { Urban construction } \\
\text { land area per capita }\end{array}$ & $\begin{array}{l}\text { It reflects the pressure on the ecosystem due to the } \\
\text { consumption of ecological resources by urban } \\
\text { construction. }\end{array}$ & $\begin{array}{l}\text { Urban construction land area per capita }=\text { Total } \\
\text { urban construction land area / Total permanent } \\
\text { population }\end{array}$ \\
\hline & $\begin{array}{l}\text { Land reclamation } \\
\text { rate }\end{array}$ & $\begin{array}{l}\text { It reflects the degree to which the land can be developed, } \\
\text { namely the pressure of land on the ecosystem. }\end{array}$ & $\begin{array}{l}\text { Land reclamation rate }=\text { Farmland area } / \text { total } \\
\text { land area } \times 100 \%\end{array}$ \\
\hline & $\begin{array}{l}\text { Proportion of area } \\
\text { affected by natural } \\
\text { disasters }\end{array}$ & $\begin{array}{l}\text { It reflects the ability of natural disasters to threat and } \\
\text { destroy the ecosystem, namely the pressure of disasters on } \\
\text { the ecosystem. }\end{array}$ & $\begin{array}{l}\text { Proportion of area affected by natural disasters }= \\
\text { Area affected by natural disasters / Farmland area } \\
\times 100 \%\end{array}$ \\
\hline & $\begin{array}{c}\text { Energy consumption } \\
\text { per unit of GDP }\end{array}$ & $\begin{array}{l}\text { It reflects the direct pressure on the urban ecosystem due } \\
\text { to the consumption of energy by urban economic } \\
\text { development. }\end{array}$ & $\begin{array}{l}\text { Energy consumption per unit of GDP = Total } \\
\text { energy consumption / Total GDP }\end{array}$ \\
\hline \multirow{4}{*}{ State } & Evenness index & $\begin{array}{l}\text { It reflects the evenness of the distribution of land types in } \\
\text { area. }\end{array}$ & $\begin{array}{l}E=H / H_{\max } \\
\text { where: } E \text {-Evenness index; } \\
H \text {-Diversity index; } \\
H_{\max } \text {-Maximum diversity index }\end{array}$ \\
\hline & $\begin{array}{l}\text { Shannon diversity } \\
\text { index }\end{array}$ & It reflects the landscape diversity. & $\begin{array}{l}H T=-\sum_{i=1}^{m}\left(P_{i} \ln P_{i}\right) \\
\text { where: } H T-\text { Shannon diversity index; } \\
P_{i} \text {-Proportion of land type } i \\
m-\text { Number of land types }\end{array}$ \\
\hline & Aggregation index & It reflects the aggregation degree of landscape types. & $\begin{array}{l}A I_{i}=\frac{e_{i i}}{\max \_e_{i i}} \\
\text { where: } A I_{i} \text {-Aggregation degree of a particular } \\
\text { landscape type; } \\
e_{i l} \text {-Number of common edges in a grid of type } i \\
\text { from its neighbours; } \\
\text { max_ } e_{i i} \text {-Maximum possible number of common } \\
\text { edges between edges of type } i\end{array}$ \\
\hline & $\begin{array}{l}\text { Interspersion and } \\
\text { juxtaposition index }\end{array}$ & $\begin{array}{l}\text { It reflects the overall interspersion and juxtaposition of } \\
\text { various types of patches. }\end{array}$ & $\begin{array}{l}\text { The percent probability of landscape patches } \\
\text { neighbouring the adjacent patches. }\end{array}$ \\
\hline
\end{tabular}




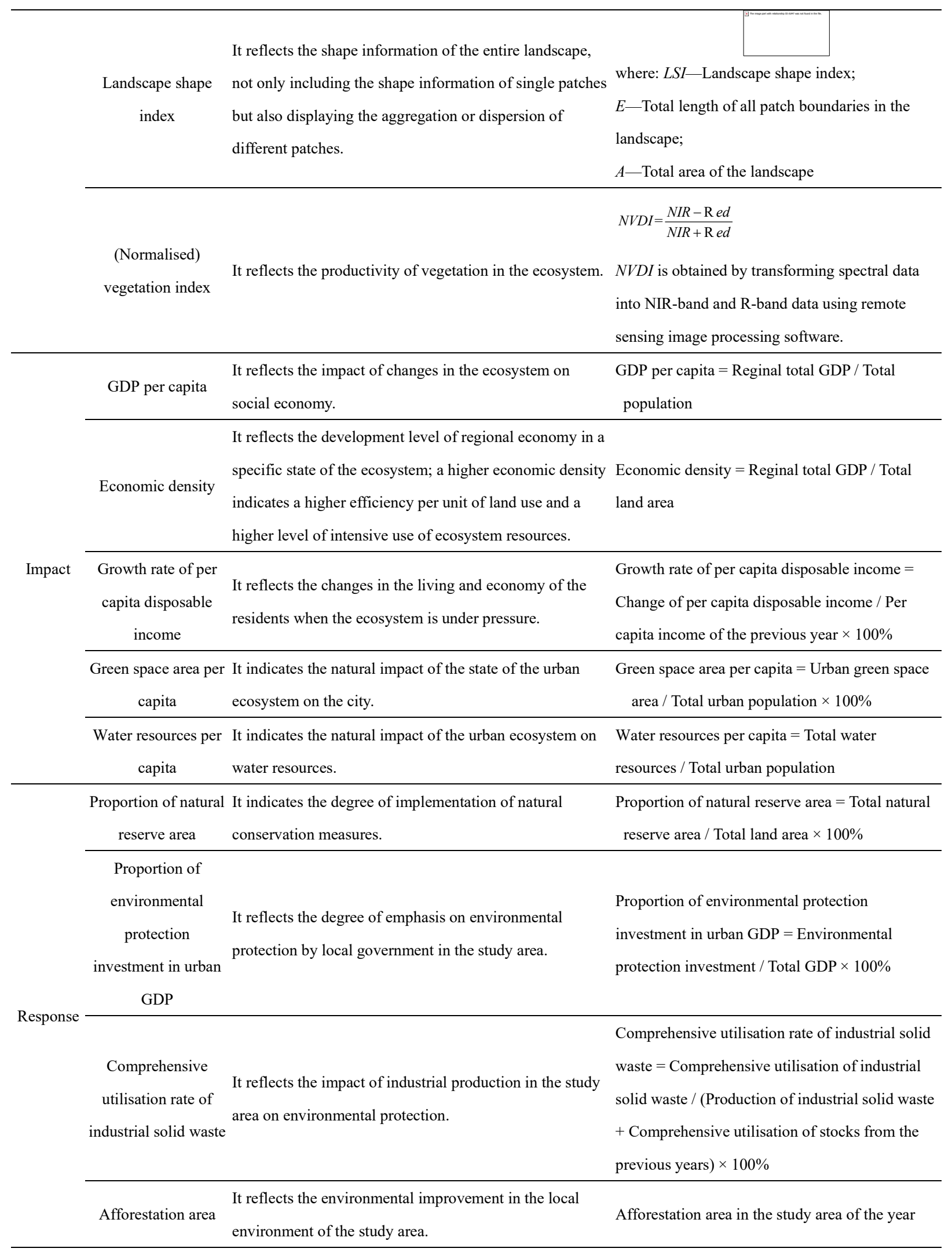

\section{The indicator system for urban ecosystem health assessment in Kunming}


The results of the indicators for the urban ecosystem health assessment in Kunming based on the constructed model and the data from Kunming across three different periods (2006, 2011 and 2016) are shown in Table 2.

Table 2 Results of the indicators for urban ecosystem health assessment in Kunming

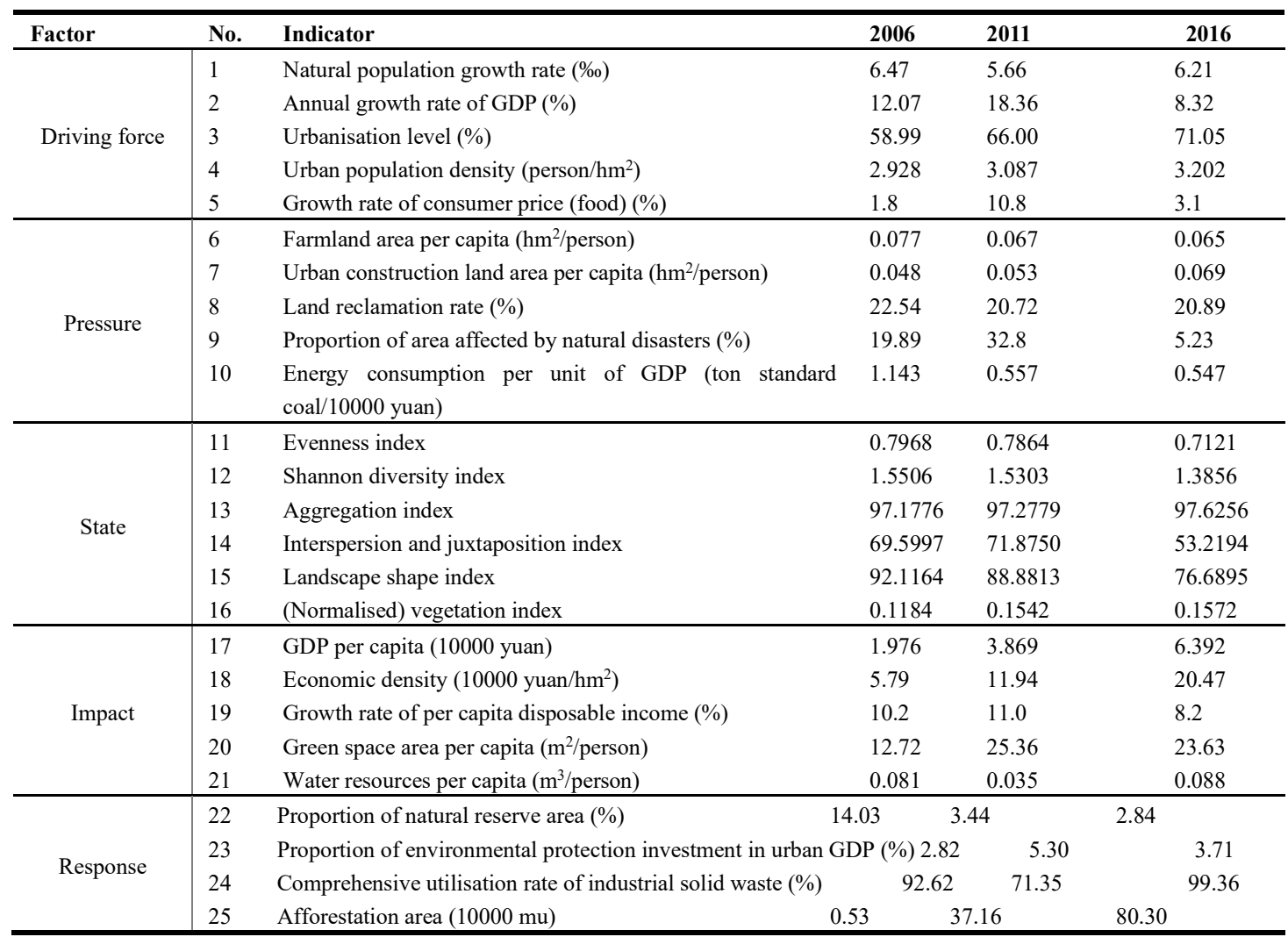

\section{Assessment of urban ecosystem health in Kunming}

We assess the indicators for the DPSIR model of Kunming using the entire-array-polygon method. The specific steps included standardising the indicator values, drawing the polygon graphs and interpreting the assessment results.

\section{Standardising the indicator values}

To eliminate the dimension effects of different indicators, we standardised all the indicators using the hyperbolic function in the $\mathrm{R}$ environment (Wang et al. 2018). The results 
are summarised in Table 3.

Table 3 Standardised values of the indicators for urban ecosystem health assessment

\begin{tabular}{|c|c|c|c|c|}
\hline \multirow{2}{*}{ Factor } & \multirow{2}{*}{ Indicator } & \multicolumn{3}{|c|}{ Year } \\
\hline & & 2006 & 2011 & 2016 \\
\hline \multirow{5}{*}{$\begin{array}{l}\text { Driving } \\
\text { force }\end{array}$} & Natural population growth rate & -0.622 & -0.664 & -0.635 \\
\hline & Annual growth rate of GDP & -0.366 & -0.136 & -0.531 \\
\hline & Urbanisation level & 0.662 & 0.739 & 0.788 \\
\hline & Urban population density & -0.817 & -0.807 & -0.801 \\
\hline & Growth rate of consumer price & -0.885 & -0.420 & -0.807 \\
\hline \multirow{5}{*}{ Pressure } & Farmland area per capita & -0.997 & -0.998 & -0.998 \\
\hline & Urban construction land area per capita & -0.999 & -0.998 & -0.997 \\
\hline & Proportion of area affected by natural disasters & -0.087 & 0.247 & -0.687 \\
\hline & Land reclamation rate & -0.007 & -0.061 & -0.056 \\
\hline & Energy consumption per unit of GDP & -0.927 & -0.965 & -0.966 \\
\hline \multirow{6}{*}{ State } & Shannon diversity index & -0.901 & -0.902 & -0.911 \\
\hline & Evenness index & -0.949 & -0.950 & -0.955 \\
\hline & Aggregation index & 0.986 & 0.987 & 0.989 \\
\hline & Interspersion and juxtaposition index & 0.954 & 0.932 & 0.838 \\
\hline & Landscape shape index & 0.774 & 0.796 & 0.590 \\
\hline & Vegetation index & -0.994 & -0.991 & -0.992 \\
\hline \multirow{5}{*}{ Impact } & GDP per capita & -0.874 & -0.762 & -0.626 \\
\hline & Economic density & -0.657 & -0.372 & -0.069 \\
\hline & Green space area per capita & -0.340 & 0.070 & 0.024 \\
\hline & Growth rate of per capita disposable income & -0.446 & -0.411 & -0.537 \\
\hline & Water resources per capita & -0.996 & -1.000 & -0.995 \\
\hline \multirow{4}{*}{ Response } & Proportion of natural reserve area & -0.289 & -0.787 & -0.822 \\
\hline & Proportion of environmental protection investment in urban GDP & -0.823 & -0.683 & -0.771 \\
\hline & Comprehensive utilisation rate of industrial solid waste & 0.958 & 0.791 & 1.000 \\
\hline & Afforestation area & -0.967 & 0.335 & 0.868 \\
\hline
\end{tabular}

\section{Entire-array-polygon drawings of single indicators and analysis results}

Using the standardisation results of the indicator values (Table 7), we drew the polygon graphs of single indicators in each factor layer (Fig. 4). 


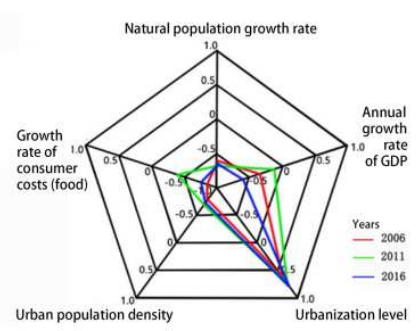

(a) Drive force factor polygon

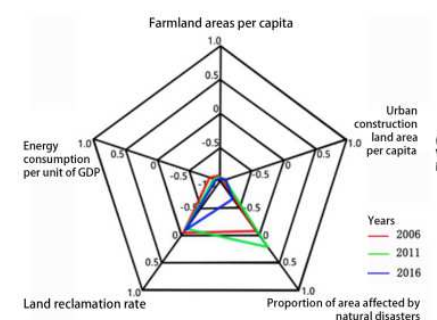

(b) Pressure factor polygon

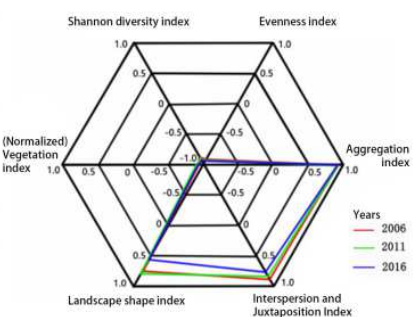

(c) State factor polygon

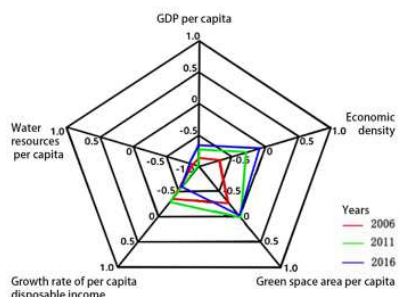

(d) Impact factor polygon

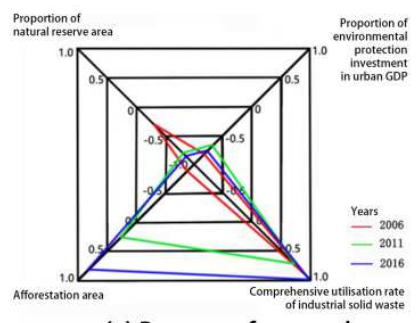

(e) Response factor polygon

Fig. 4 Entire-array-polygons of single indicators

1) The health of the urban ecosystem is significantly affected by driving force factors associated with urban development

During the study period, the continuous increase in urban extent was accompanied by an increase in urban population density, showing isotropic changes over time. However, the annual growth rate of urban GDP exhibited a decreasing trend over the study period, and economic development evolved from a phase of simply seeking rapid development to a new phase of sustainable development. Both the natural growth rate of the urban population and the growth rate of consumer costs first decreased and then increased from 2006 to 2016, and these changes were associated with the population migration from suburbs and rural areas to urban central districts seeking high-quality educational resources. This resulted in the growth of the urban population at consistently high rates and, thus, challenged the carrying capacity of the ecological environment. Variations in the growth rate of consumer costs for food may 
reflect a decrease in the farmland area in the city, leading to a shortage of food, or it may reflect the improved quality of life of urban residents through economic activities, which increases the price paid by the ecosystem.

2) Pressure factors such as energy consumption and disasters negatively affect the health of the urban ecosystem

A negative correlation was found between the indicator values of farmland area per capita and construction land area per capita. The expansion of urban construction constantly accelerated, often on converted farmland. Additionally, the reclamation rate of urban land decreased year by year. However, energy consumption per unit of GDP also showed a downward trend over time, suggesting that the government had successfully implemented the concept of energy conservation and emissions reduction. The proportion of land affected by natural disasters peaked in 2011, which directly led to the increasing fragility of the urban ecosystem, a reduction in the self-healing capacity of the environment, and an increasing pressure from disasters on the ecosystem. Long-term drought exposed the problems associated with a lag in infrastructure construction such as urban water conservancy. The level of urban water storage capacity was low, leading to an expansion in the drought-affected area, with serious consequences.

3) Landscape pattern indices represent the state of urban ecology at the landscape level

From 2006 to 2016, the diversity and evenness indices gradually decreased, showing that the emergence of pollutants in areas represented by Dianchi Lake damaged the normal ecological flows in the urban ecosystem, which caused a gradual decline in diversity and a 
reduction in plant species in Kunming. In contrast, the aggregation index increased over time in the three study periods because urban construction showed aggregated development, while the remaining landscape patches tended to be fragmented. This resulted in evident patch aggregation but an irregular distribution of landscape types. The interspersion and juxtaposition index reached its peak value in 2011, showing the characteristics of arid areas. Taking into account the variation in the proportion of area affected by natural disasters pressure factor, it can be seen that when Kunming, as a plateau city surrounded by mountains, suffered from drought, the irregular distribution of water led to a complex landscape spatial structure. Overall, the landscape pattern indices suggested that the urbanisation process was accelerating and urban construction land tended to aggregate in Kunming, which strongly disturbed the landscape elements.

4) Social and economic impacts can guide the healthy trends of the urban ecosystem

During the study period, both the GDP per capita and economic density in Kunming displayed an evident upward trend over time, indicating that the urban economy was developing rapidly and that economic benefits were improving, based on ecosystem services. The per capita disposable income of urban residents increased continuously, but the growth rate declined over time, which was consistent with the characteristics of the environmental Kuznets curve. There was a rapid decrease in water resources per capita in 2011 mainly because of continuous drought in Kunming from 2009 to 2011. After 2011, the drought subsided, resulting in increased water yield in rivers and lakes; meanwhile, the storage capacities of reservoirs and ponds also increased. The water resources per capita returned to 
normal levels in 2016. In terms of the green space area per capita, there was a dramatic increase from 2006 to 2011 followed by a slight decrease from 2011 to 2016; overall, the growth in area was rapid. Changes in the ecosystem conditions drove continuous socio-economic development while compensating for the loss of ecological resources.

5) Changes in the indicators of response factors show the health of the urban ecosystem was disturbed by social and human factors

In the study period, the proportion of natural reserve area declined substantially from 2006 to 2016. There were also many problems associated with low management effectiveness, such as no relevant institutions, which resulted in the low natural response of the reserves and decreased biodiversity year by year. However, the afforestation area increased year by year because a large number of afforestation projects were carried out, and this result indicated that the implementation of environmental protection policies, such as returning farmland to forest, had made some progress. The proportion of environmental protection investment in urban GDP initially increased from 2006 to 2011 and then decreased from 2011 to 2016. After a considerable decrease in 2011 , the comprehensive utilisation rate of industrial solid waste increased in 2016. Changes in these two indicators were not synchronised with those of the other indicators including urbanisation level, per capita GDP and economic density. The variable efficiency of garbage and waste disposal, together with the problems associated with incomplete implementation of environmental protection policies, low efficiency of environmental protection and development before governance, all had a negative impact on the natural response of the urban ecosystem in Kunming. 


\section{Calculation of the overall index value and assessment of the health level}

The criteria for assessing the health state of the urban ecosystem are listed in Table 4.

Table 4 Criteria for assessing the health state of the urban ecosystems

\begin{tabular}{ccccc}
\hline Level & Unhealthy & Relatively healthy & Healthy & Very healthy \\
\hline Interval & $<0.25$ & $0.25-0.5$ & $0.5-0.75$ & $>0.75$ \\
\hline
\end{tabular}

The overall indicator value was calculated from the standardised values of the different indicators in each year using Eq. (1). The overall assessment results for the health state of the urban ecosystem in Kunming during the study period are summarised in Table 5.

Table 5 Assessment of the health state of the urban ecosystem in Kunming during three different periods $(2006,2011$ and 2016)

\begin{tabular}{cccc}
\hline Year & 2006 & 2011 & 2016 \\
\hline Overall indicator value & 0.1796 & 0.2432 & 0.2186 \\
\hline Health level & Unhealthy & Unhealthy & Unhealthy \\
\hline
\end{tabular}

The results indicated that the health state of the urban ecosystem in Kunming was classified as unhealthy across all the three years, 2006, 2011 and 2016. This suggested that the urban ecosystem of Kunming did not reach a coordinated state from the five perspectives of driving force-pressure-state-impact-response during the study period. The human-environment relationship was uneven. On the one hand, sustained economic growth was maintained; on the other hand, natural disasters occurred frequently, ecological 
self-healing capabilities declined and the city did not implement environmental protection response measures effectively.

Early warning and rehabilitation strategies for the health of the urban ecosystem in

\section{Kunming}

Prediction of the health state of the urban ecosystem in Kunming

On the basis of the overall indicator values of the three periods in Kunming, we used grey system forecasting theory to predict the health state of the urban ecosystem in Kunming over the next 10 years.

$$
X^{(0)}=\left(x^{(0)}(1), x^{(0)}(2), x^{(0)}(3)\right)=(0.1799,0.2432,0.2186)
$$

where $x^{(0)}(k)(k=1,2,3)$ and $x^{(0)}(1)=0.1799$ was obtained from 2006, $x^{(0)}(2)=0.2432$ was obtained from 2011, and $x^{(0)}(3)=0.2186$ was obtained from 2016. Because of the scattered and irregular values of the data, proportional interval forecasting was an appropriate method to use(Liu et al. 2017 ).

The calculation was conducted using Eqs. (2-7), and the detailed procedure is not described again here. We obtained the following result:

$$
\Delta_{s \max }=02432, \Delta_{u \min }=0.1799
$$

The findings indicate that if the current state continues to evolve, the predicted values of 2021 and 2026 are both within the range [0.1799-0.2432]; that is, the urban ecosystem will continue to be in an unhealthy state. Without taking strong measures, the health of the urban ecosystem will fail to improve and may continue to deteriorate in Kunming.

\section{Strategies for ecosystem rehabilitation in Kunming}


1) Transform the urban development model into a positive driving force

We suggest scientifically designing the development relationship between central urban districts and surrounding areas, adjusting the economic structure and improving the quality of development in Kunming. Furthermore, it is important to explore the development potential of surrounding counties and cities, and guide the sustainable allocation of industries, populations, employment, facilities and resources. The government should strengthen infrastructure construction in these counties and cities and maintain the flow of educational resources, making them a positive driving force for the development of ecosystem health in Kunming.

2) Reduce pressure on the ecosystem and adjust the industrial structure

We recommend adjusting the industrial structure in Kunming by gradually eliminating energy-intensive resource industries such as mining and accelerating industrial transformation and upgrades. Additionally, the distribution of industrial parks should be arranged rationally to facilitate the adjustment of industrial structure and improve the technological level of industrial development. It is necessary also to improve production technologies and reduce industrial energy consumption. Strategic emerging industries can be developed, such as low-carbon industries, using new energy sources and new materials, with a focus on increasing the proportion of tertiary industry. Other recommendations are to monitor changes in the ecological environment, maintain a high awareness of disaster prevention, increase the response speed of disaster relief and reduce the probability of recurrent disasters. Efforts should be made to improve the resilience to urban disasters and 
reduce the pressure on ecosystem health.

3) Improve the state of resources and the environment and strengthen nature conservation

Ecological conservation should be enhanced and the balance of urban ecology maintained.

It is important to reduce the complete destruction of large landscape patches caused by resource exploitation, mitigate the irreversible negative impact of production activities on the ecosystem, and decrease the damage to landscape morphology because of human transformation. The vegetation coverage in urban land can be improved, thereby reducing the dispersion of small landscape patches, protecting the natural characteristics of landscape forms, and promoting the connectivity of ecological landscapes. Attention should be paid to the construction of green spaces in the urban area of Kunming and of ecological corridors in the surrounding counties and cities, which can provide food sources and water channels for animals and plants, and promote greater biodiversity. Moreover, ecological restoration provides an opportunity to improve urban disaster resilience, effectively connect ecological flows between the city and the outer suburbs, enhance the self-healing ability of the environment, and reduce the negative impact of natural disasters. This will ultimately protect the integrity of the ecological landscape and improve the state of ecosystem health.

4) Reduce negative impacts and strengthen the construction and protection of blue-green space

We propose that plans are made to strengthen and increase urban greening, enhance the maintenance of urban vegetation and improve the survival rate of vegetation and soil water retention. Meanwhile, the government should strengthen the implementation of various water 
pollution control measures, increase the water conservation capacity and mitigate the negative impacts of lagged construction of green space, inadequate soil water conservation and frequent occurrence of droughts in Kunming, to maintain a balanced relationship between urban development and ecological well-being.

5) Positively respond to the healthy development of the urban ecosystem by increasing ecological conservation investment

We suggest enhancing protection assessments in the natural environment of Kunming, rationally delineating ecological red lines, increasing the area of reserves and maintaining an ecological balance in urban areas. Furthermore, a mature administrative organisation can be established to improve the efficiency of natural resource conservation and comprehensively increase the conservation and management strength of reserve areas. Moreover, we recommend improving urban ecosystem health by implementing response measures such as increased ecological conservation investment and improved environmental protection efficiency.

\section{Discussion}

The results showed that: (1) The DPSIR model successfully reflected urban, natural, and socio-economic characteristics, and clearly showed the causal relationship between the state of urban ecosystem health and the five influencing factors. Thus, this model provided an effective tool to determine the causal relationship between urban development and ecological environment problems(Xiong,2020). The selected indicators reflected the characteristics of Kunming as a plateau city surrounded by mountains, including fragile ecosystems, frequent 
natural disasters, and poor ecological restoration potential. Therefore, these indicators could comprehensively and systematically reflect the health state of the urban ecosystem in Kunming. The model showed that the driving force factor initiated the changes in the entire ecosystem, and its impact was the most critical underlying cause of an unhealthy urban ecosystem. In terms of pressure, the assessment indicators were the manifestation of the driving force indicators, and they reflected the direct cause of changes in the ecosystem. The state of the ecosystem referred to its situation under pressure. The impact factor explained the positive or negative impact on the social and economic structure posed by the state of the ecosystem under pressure. The response factor affected the state of the ecosystem through corresponding response measures. Under the combined effects of all the factors, the overall indicator values for the health state of the urban ecosystem in Kunming (2006, 2011 and 2016) were estimated to be $0.1796,0.2432$ and 0.2186 , all of which were classified as unhealthy. The health of the urban ecosystem can be restored through controlling the driving force, reducing the pressure, improving the state, reducing the impact, and promoting the response. (2) The entire-array-polygon method was combined with the DPSIR model to standardise indicators with different unit dimensions. The graphical presentation of entire-array-polygons allows for visual comparison of the dynamic changes between various indicators and factors. In this way, the overall changes of various factors and indicators in each period were displayed, which gave clear quantitative results for the research and facilitated the comparison of the final results over different periods(Zhang et al.2016). Finally, relatively accurate results of the overall assessment of urban ecosystem health were obtained, which 
have universal applicability. (3) Given the incomplete future information, the grey system forecasting method was used to predict the future health level of the urban ecosystem, based on the above-mentioned multi-period overall indicator values for the current health state of the urban ecosystem. The results provided an early warning for the health state of the urban ecosystem in Kunming, which will continue to be poor if the current trajectory is maintained. Thus, associated rehabilitation measures were proposed in a targeted manner, based on science and pertinent to the main problems(Liu et al. 2017 ).

Additionally, this was a quantitative study assessing the overall ecosystem health in Kunming, but we did not look at the spatial distribution of ecosystem health state in counties and cities within Kunming. Exploring the distribution of the health state within the study area can better show the relationships between neighbouring sub-areas within the region. Such research can also help researchers to analyse more detailed humanistic and socioeconomic relationships within the scope of the study, and it is useful to enhance the pertinence of the strategies for improving the health state of the urban ecosystem. In future studies, we should consider investigating the spatial distribution patterns of ecosystem health within the study area.

Note: All drawings were prepared by Yang Liu and Xue Huang.

Acknowledgments: This work was supported by the National Natural Science Foundation of 
China under Grant No. 52078222. We thank Leonie Seabrook, PhD, from Liwen Bianji, Edanz Group China (www.liwenbianji.cn/ac), for editing the English text of a draft of this manuscript.

Availability of data and material: We utilized both remote sensing image data and basic data. For secondary data, we duly referred to the statistical data published by the Kunming Municipal Government. Among them, the remote sensing image data is the landsat TM satellite image map of Kunming City with a resolution of $30 \mathrm{~m}$. The data comes from the geospatial data cloud. The basic data includes geographic data such as roads, rivers, and administrative divisions of Kunming in three stages, as well as socioeconomic data such as population and humanities in each study year.

Funding: The manuscript with a title "Modelling Past and Future Urban Ecosystem Health Assessment-A Case Study of Kunming” is prepared by Prof Li and her research team. This work was supported by the National Natural Science Foundation of China under Grant No. 52078222.

Comflicts of interest/competing interests: The authors confirm that no conflict of interest are associated in conducting the research and in preparing the manuscript. Personal or other relationships with other people or organizations have no influence on the research. 


\section{Reference}

Cao C., Li XY (2018) Health assessment of river ecosystem at the district and county scales: A case study of Fangshan district in Beijing. Acta Ecologica Sinica 38(12):4296-4306. https://doi.org/10.5846/stxb201712312362.

Chen Q, Chen YH, Wang MJ, Jiang WG, Hou P, Li Y (2015) Ecosystem quality comprehensive evaluation and change analysis of Dongting Lake in 2001-2010 based on remote sensing. Acta Ecologica Sinica 35(13):4347-4356. https://doi.org/10.5846/stxb201403250557.

Cheng L, Dong J (2013) Suitability Evaluation of"Linking the Increase with Decrease in Land Used for Urban and Rural Construction"Based on Entire-Array-Polygon Evaluation Model. Research of Agricultural Modernization 34(4):472-476.

Deng XJ, Xu YP, Zhai LX., Liu Y, Li Y (2014) Establishment and application of the index system for urban river health assessment. Acta Ecologica Sinica 34(4): 993-1001 https://doi.org/10.5846/stxb201209221339.

Du HL., Li X., Li B (2018). Comparative Study on Evaluation Standard of Green Ecological District. Urban Development Studies 25(06): C16-C20.

François C, Gondran N, Nicolas JP, Parsons D (2017) Environmental assessment of urban mobility: Combining life cycle assessment with land-use and transport interaction modeling-Application to Lyon (France). Ecological Indicators https://doi.org/72:597-604. doi: 10.1016/j.ecolind.2016.07.014

Guan DJ, Su Y, He ZC (2014) Dynamic Evaluation on Urban Ecosystem Health Based on Fuzzy Mathematics Model. Research of Soil and Water Conservation 21(5): 150-156. https://doi.org/10.13869/j.cnki.rswc.2014.05.027.

Karen T, Katharina H, Bernd K, Stefan S, Sergio GP (2010) Does research applying the DPSIR framework support decision making? Land Use Policy (29):102-110. https://doi.org/10.1016/j.scitotenv.2008.08.004.

Liu SF, Yang YJ, Wu LF (2017) Grey System Theory and Its Applications, Science Press, Beijing, 142-144. ISBN: 9787030273925

Liu YX, Peng J, Wang A, Xie P, Han YN (2015) New research progress and trends in ecosystem health. Acta Ecologica Sinica 35(18): 5920-5930. https://doi.org/10.5846/stxb201401060032.

Lu YL, Wang RS, Zhang YQ, Su HQ, Wang P, Jenkins A, Ferrier RC, Bailey M., Squire G (2015) Ecosystem health towards sustainability. Ecosystem Health and Sustainability 1(1): 1-15. https://doi.org/10.1890/EHS14-0013.1.

Liu, C. S., Wang, Q., and Zhou, X. L. 2016. "Beijing City Environment Quality Evaluation Based on Two-dimension Vector Evaluation System." Urban Development Studies 23 (3) : 38-42,110.

Mahdi A, Hosseini A, Pourahmad A, Hataminejad H (2016) Analysis of effective environmental factors an urban health, a case study of Qom, Iran. Habitat International 55: 89-99. https://doi.org/10.1016/j.habitatint.2016.03.001.

Naeema JZ, Paul MS (2021) Urban ecosystems and ecosystem services in megacity Dhaka: mapping and inventory analysis. Urban Ecosystems 06: 1-14. https://doi.org/10.1007/s11252-020-01076-1.

Pinto U, Maheshwari BL (2011) River health assessment in peri-urban landscapes: An application of multivariate analysis to identify the key variables. Water Research 45(13): 3915-24. https://doi.org/10.1016/j.watres.2011.04.044.

Quan JT, Yang YF, Zhou JX (2020) Analysis and Prediction of Spatial and Temporal Evolution of Land Resource Carrying Capacity in Henan Province. Research of Soil and Water Conservation 27(2) : 315-322. https://doi.org/10.13869/j.cnki.rswc.2020.02.044.

Rapport DJ, Gandel CL, Calow P (1994) Evaluating and monitoring the health of large scale ecosystem. Berlin:Springer verlag.

Steward TA., Pickett M.L, Cadenasso DL, Childers MJ, Mcdonnell, Zhou WQ (2016) Evolution and future of urban ecological science: ecology in, of, and for the city. Ecosystem Health and Sustainability 2(7):1229-1244. 
https://doi.org/10.1002/ehs2.1229.

Su MR, Yang ZF, Chen B (2012) Ecosystem health assessment of urban clusters: Method and application. Procedia Environmental Sciences 13(3):1134-1142. https://doi.org/10.1016/j.proenv.2012.01.106.

Su M, Fath BD, Yang Z (2010) Urban ecosystem health assessment: A review. Science of the Total Environment 408(12): 2425. https://doi.org/10.1016/j.scitotenv.2010.03.009.

Wang ZY, Ma JJ, Chen XX, Zhao D, Teng T, Yang YC (2018) Assessment on Ecological Health of Three Developed Core Districts in Xi'an Based on Emergy Analysis. Research of Soil and Water Conservation 25(4):317-323. https://doi.org/10.13869/j.cnki.rswc.20180307.001.

Wang YR, Zhang DH, Wu YL (2020) The spatio-temporal changes of forest ecological security based on DPSIR model: case study in Zhejiang Province. Acta Ecologica Sinica 40(8). https://doi.org/10.5846/stxb201903180509.

Walker C, Lampard JL, Roiko A, Tindale N, Wiegand A, Duncan P (2013) Community well-being as a critical component of urban lake ecosystem health 16:313-326. https://doi.org/10.1007/s11252-012-0256-1

Xu HT, Zhou LF, Cheng Q (2017) Study on ecosystem health evaluation and risk assessment for Linghekou wetlands based on a PSR model. Acta Ecologica Sinica 37( 24) : 8264-8274. https://doi.org/ 10.5846/stxb201611152317.

Xiong X (2020) Study on analysis and evaluation for the construction of ecological civilization about the First state-level ecological civilization demonstration. Acta Ecologica Sinica 40(14):5081-5091. https://doi.org/10.5846/stxb202001150123.

Xing, G. J., and Zhao, M. W. 2019. “Assessing the Ecological Health of Qianhe Lake Using Grey Correlation Analysis Method." Journal of Irrigation and Drainage 38(3):121-128. doi: 10.13522/j.cnki.ggps.20180306.

Yang HK, Xu ZW (2002) Discrimination of conception on ecosystem health. Journal of Chang Chun Teachers College 21: 64-67.

Yuan MN, Liu YX, Wang M, Tian L, Peng J (2019) Ecosystem health assessment based on the framework of vigor ,organization ,resilience and contribution in Guangzhou City. Chinese Journal of Ecology 38(04): 1249-1257. https://doi.org/ 10.13292/j.1000-4890.201904.026.

Zhu, J. Y., Lu, H. T., Wang, H. F., Yan, Y., and Tang, L. N. 2018. "Ecosystem health assessment of the Wenchuan earthquake hard-hit disaster areas during the recovery period." Acta Ecologica Sinica 38(24): 9001-9011. doi: $10.5846 / \mathrm{stxb} 201808081684$

Zhang FT, Wang LC, Su WC (2016) Evaluation of land ecological security in Chongqing based on the matter-element analysis-DPSIR model. China Environmental Science 36(10): 3126-3134.

Zhang LL, Zheng XQ, Yuan ZY, Cui HN (2016) Assessment on Multi-functionality of Land Use based on the Entire-array-polygon Indictor Method in Tangshan. China Land Sciences 30(6):23-32. https://doi.org/10.11994/zgtdkx.20160714.151928.

Zhou W, Cao YG, Qiao LY (2012) Urban Land Intensive Use Assessment Based on the Entire-Array-Polygon Indictor Method. China Land Sciences 26(4):84-90.

Zhu JK. (2014) A Research of Sudden Nature Disaster Risk Management in Kunming. Yunnan University. Kunming, Yunnan, China. 


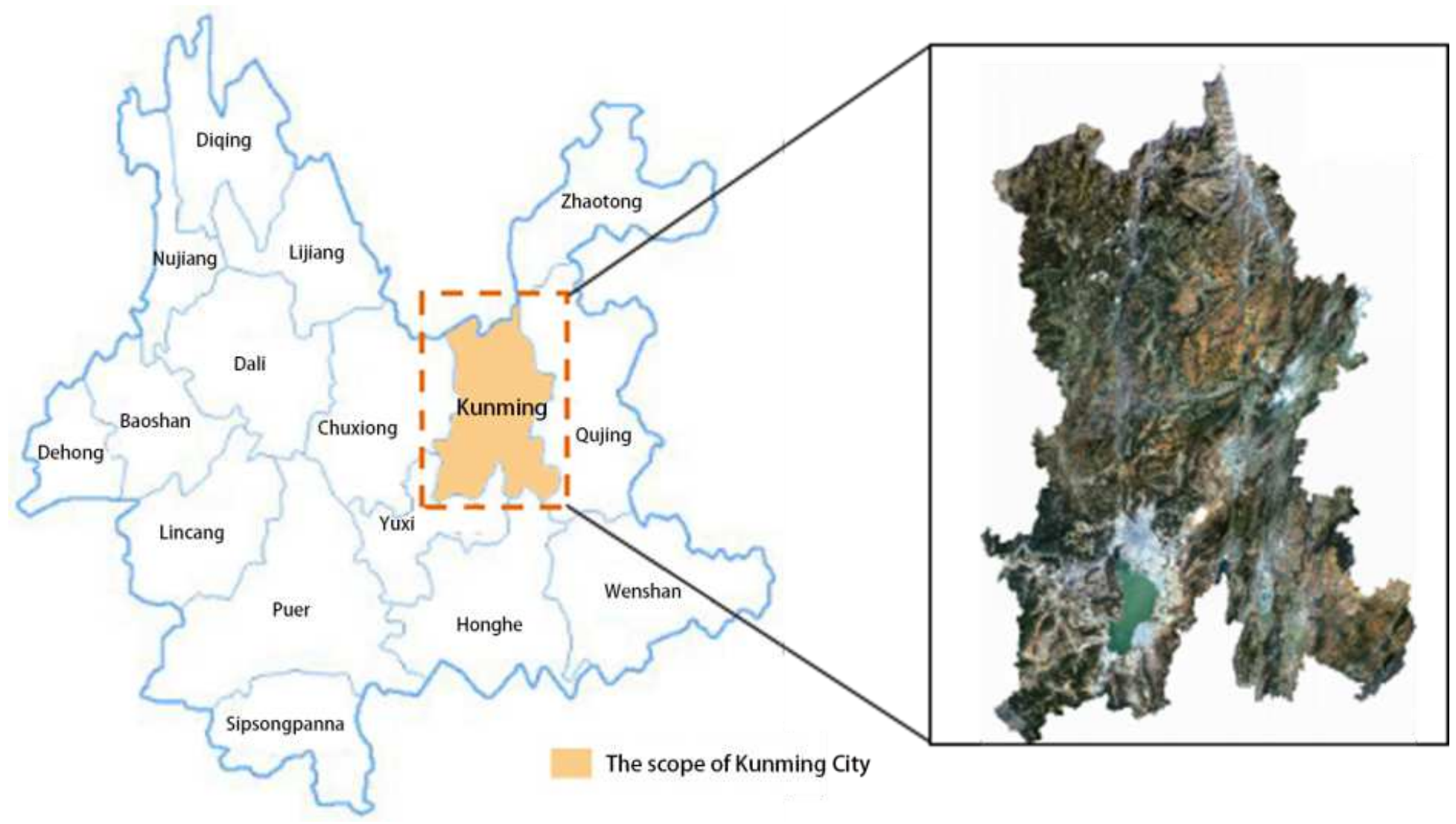

Figure 1

Scope of the study area in Kunming, Yunnan Province, China. Note: The designations employed and the presentation of the material on this map do not imply the expression of any opinion whatsoever on the part of Research Square concerning the legal status of any country, territory, city or area or of its authorities, or concerning the delimitation of its frontiers or boundaries. This map has been provided by the authors.

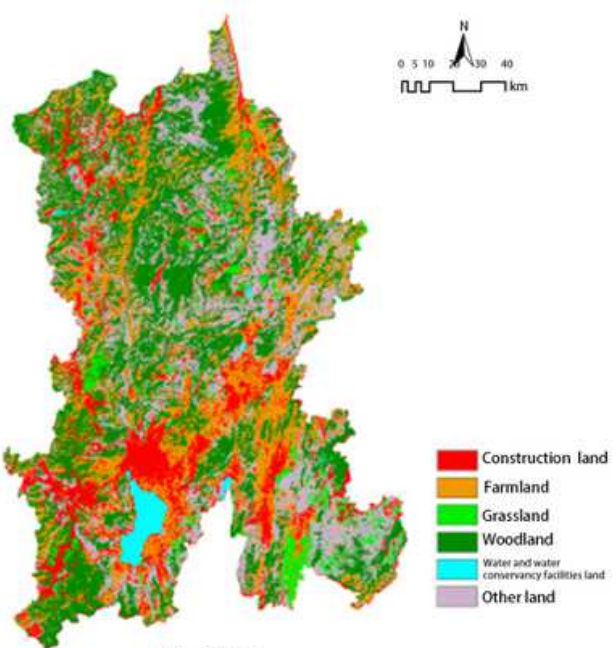

(a) 2006

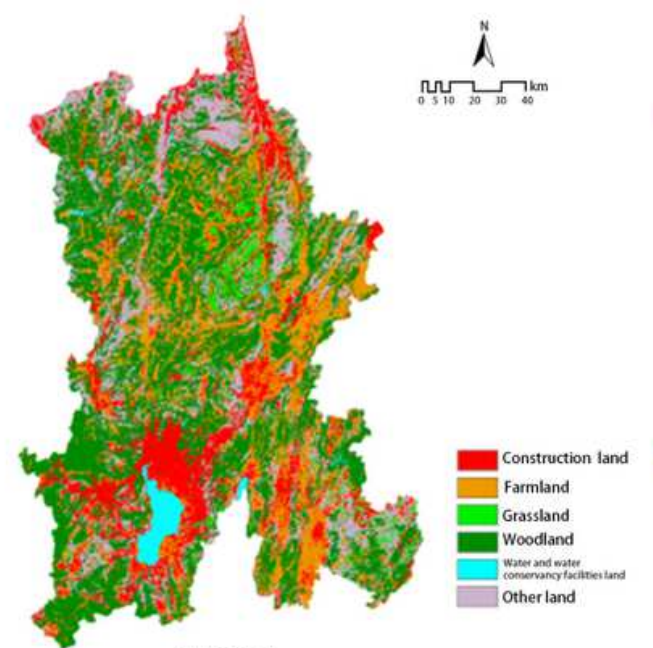

(b) 2011

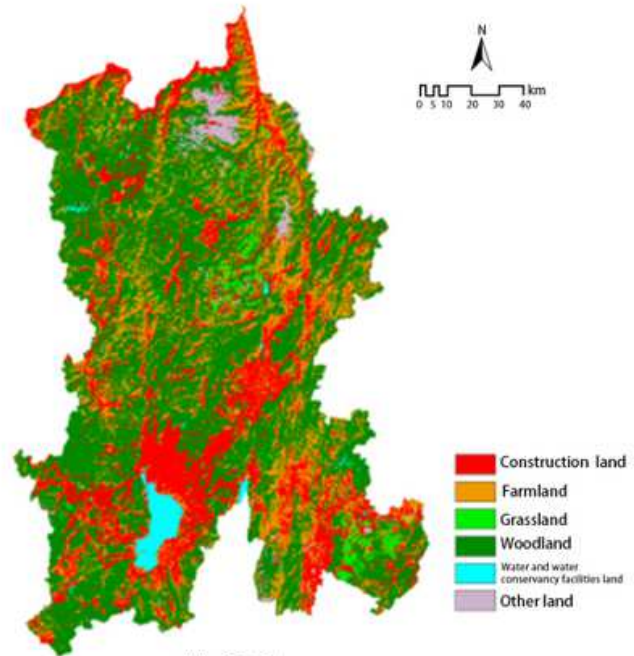

(c) 2016 
Figure 2

Land use classification in Kunming during 2006, 2011 and 2016. Note: The designations employed and the presentation of the material on this map do not imply the expression of any opinion whatsoever on the part of Research Square concerning the legal status of any country, territory, city or area or of its authorities, or concerning the delimitation of its frontiers or boundaries. This map has been provided by the authors.

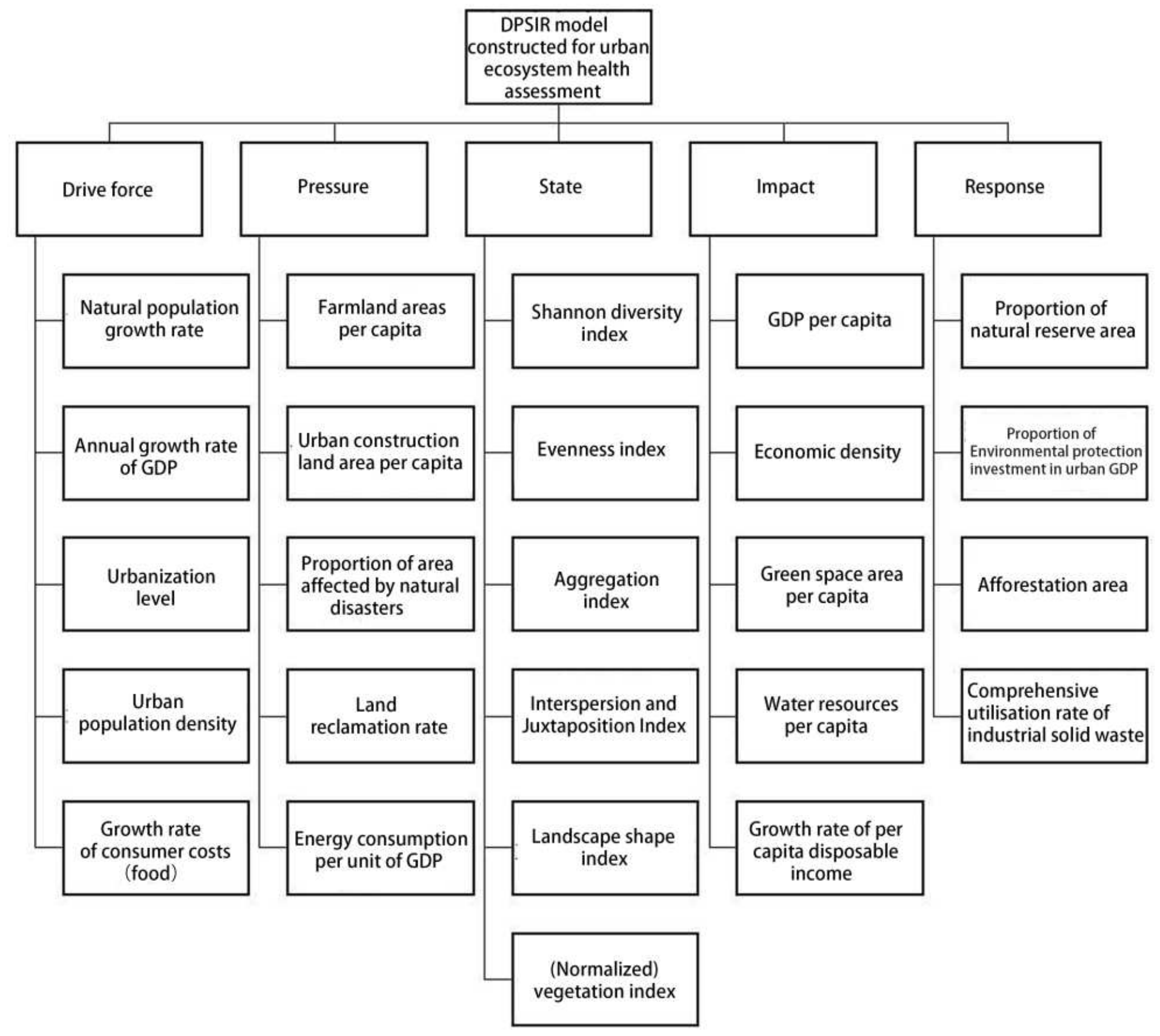

Figure 3

Diagram of the driving force-pressure-state-impact-response (DPSIR) model constructed for urban ecosystem health assessment 


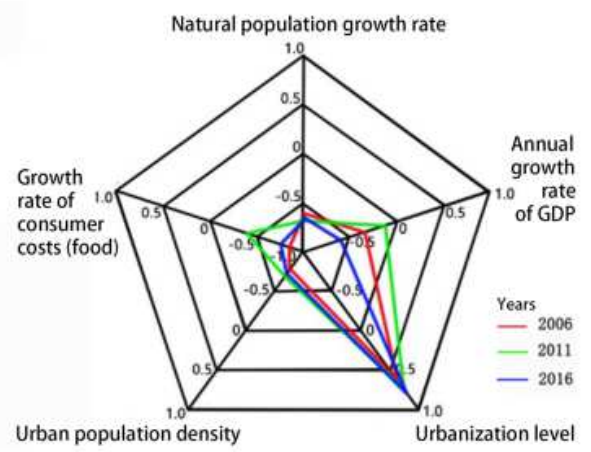

(a) Drive force factor polygon

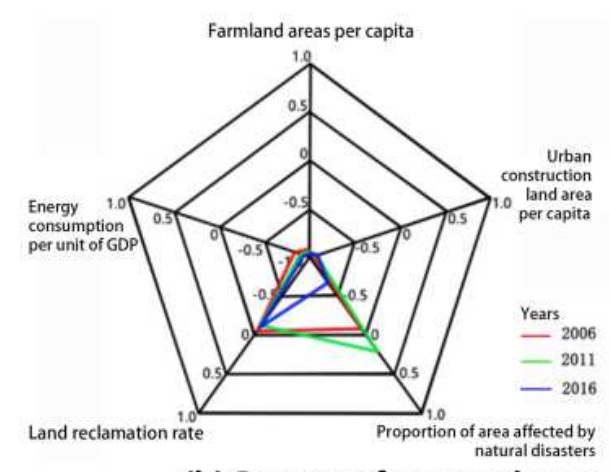

(b) Pressure factor polygon

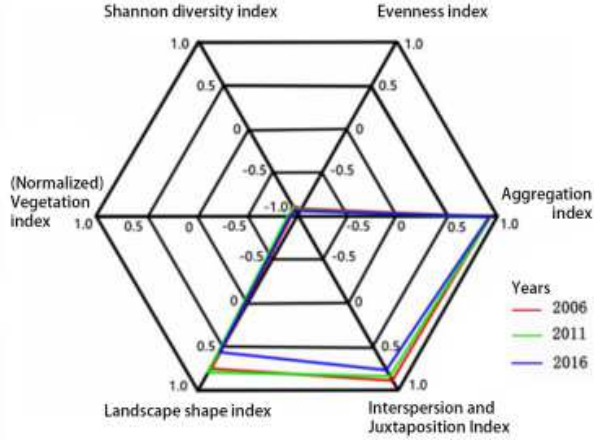

(c) State factor polygon

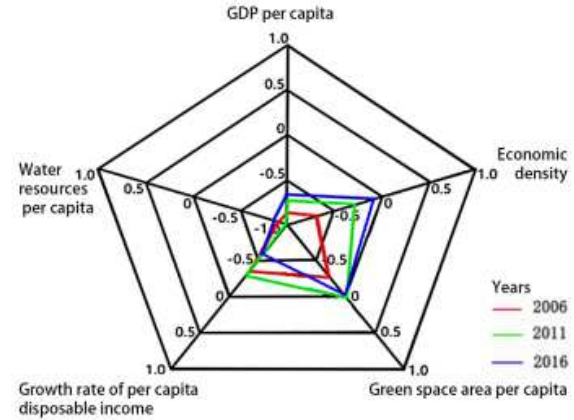

(d) Impact factor polygon

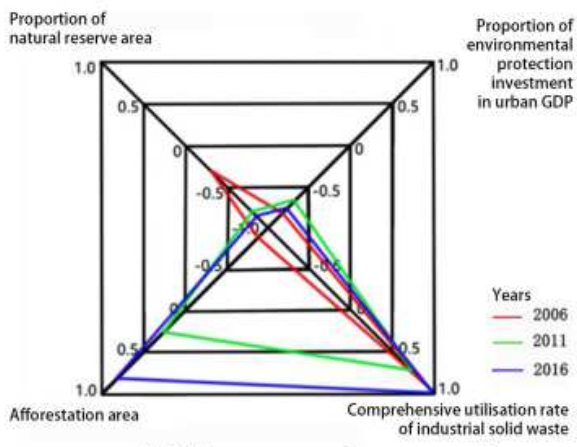

(e) Response factor polygon

Figure 4

Entire-array-polygons of single indicators 